\title{
An Isoform-specific Mutation in the Protein 4.1 Gene Results in Hereditary Elliptocytosis and Complete Deficiency of Protein 4.1 in Erythrocytes but not in Nonerythroid Cells
}

\author{
John G. Conboy, Joel Anne Chasis, Ricky Winardi, Gil Tchernia, Yuet Wai Kan, and Narla Mohandas \\ Cell and Molecular Biology Division, Lawrence Berkeley Laboratory, University of California, Berkeley, California $94720 ;$ Department \\ of Laboratory Medicine and Howard Hughes Medical Institute, University of California, San Francisco, California 94143; \\ and Hôpital Bicetre, 94270 Kremlin Bicetre, Paris, France
}

\begin{abstract}
Multiple protein 4.1 isoforms are expressed in a variety of tissues through complex alternative pre-mRNA splicing events, one function of which is to regulate use of two alternative translation initiation signals. Late erythroid cells express mainly the downstream initiation site for synthesis of prototypical 80-kD isoforms; nonerythroid cells in addition use an upstream site to encode higher molecular mass isoform(s). In this study, we examined the effects of a 5 ' gene rearrangement in a family with hereditary elliptocytosis and complete deficiency of erythrocyte 4.1 protein on 4.1 isoform expression in erythroid vs. nonerythroid cells. Patient 4.1 mRNAs from reticulocytes, fibroblasts, and $B$ lymphocytes were amplified by reverse transcriptase/polymerase chain reaction techniques and shown to exhibit a 318-nucleotide deletion that encompasses the downstream AUG, but leaves intact the upstream AUG. Immunoblot analysis revealed a total deficiency of 4.1 in patient red cells and a selective deficiency of $80-\mathrm{kD}$ isoform( $\mathrm{s}$ ) but not high molecular weight 4.1 in patient nonerythroid cells. Thus, the 4.1 gene mutation in this family produces an isoform-specific deficiency that is manifested clinically in tissue-specific fashion, such that red cells are affected but other cell types are unaffected because of tissue-specific differences in RNA splicing and translation initiation. (J. Clin. Invest. 1993. 91:77-82.) Key words: erythrocyte - alternative splicing - protein 4.1 • translation initiation $\bullet$ hereditary elliptocytosis
\end{abstract}

\section{Introduction}

Studies on red cells from patients with abnormal red cell morphology and clinically significant hemolytic anemia have focused on the structure and function of the "membrane skeleton," a highly organized network of proteins supporting the inner surface of the cell membrane. Several red cell disorders, including hereditary spherocytosis and hereditary elliptocytosis ( HE), ${ }^{1}$ can result from disruption of membrane function by

Address correspondence to John Conboy, Cell and Molecular Biology, University of California, Lawrence Berkeley Laboratory, 1 Cyclotron Road, Building 74-157, Berkeley, CA 94720. 1992.

Received for publication 28 April 1992 and in revised form 2 July

1. Abbreviations used in this paper: HE, hereditary elliptocytosis; PBGD, porophobilinogen deaminase; PCR, polymerase chain reaction; RFLPs, restriction fragment polymorphisms.

J. Clin. Invest.

(c) The American Society for Clinical Investigation, Inc.

$0021-9738 / 93 / 01 / 077 / 06 \$ 2.00$

Volume 91, January 1993, 77-82 mutation of the gene(s) for major membrane skeletal proteins including protein 4.1, $\alpha$ - and $\beta$-spectrin, ankyrin, and band 3 (1).

Although most of these skeletal proteins were originally thought to be restricted to erythroid cells, it is now known that closely homologous proteins are also found in most nonerythroid cell types. Interestingly, the nonerythroid homologs often vary with respect to size, sequence, or subcellular location compared to the red cell forms. These different but homologous forms (isoforms) of membrane proteins may arise as products of distinct genes, or by differences in expression of a single gene in erythroid versus nonerythroid cells. One well-known mechanism for differential gene expression is alternative premRNA splicing, a process by which a single gene can generate different isoforms in different tissues.

Protein 4.1 is a key membrane skeletal protein which plays an important role in determining red cell shape and integrity through specific interactions with other skeletal and membrane components. The major form of protein 4.1 in red cells is a polypeptide of $\sim 80 \mathrm{kD}$, while nonerythroid cells contain a heterogeneous array of 4.1 polypeptides that range in size from 30 to $210 \mathrm{kD}(2)$. Despite the size and structural variations among these proteins, all appear to be encoded by a single large gene ( $>100 \mathrm{~kb})(3)$. Isoform variation is generated by alternative splicing of the 4.1 pre-mRNA transcribed from this gene, a complex process in which discrete exons are either spliced in (included) or spliced out (deleted) to produce an array of mature 4.1 messenger RNAs that can be translated into different protein isoforms (Fig. 1 $A$ ) (4-7). In addition, either of two potential translation initiation sites (denoted by the trinucleotide AUG) can be used depending on whether the upstream (more $5^{\prime}$ ) or downstream sites are included in the mature mRNA $(5,7)$ (Fig. $1 B$ ). Reticulocyte 4.1 mRNAs possess only the downstream AUG and can synthesize only the $80-\mathrm{kD}$ red cell isoform, while nucleated erythroid progenitors and nonerythroid cells also contain the upstream initiation sites and synthesize larger protein 4.1 isoforms having an elongated $\mathrm{NH}_{2}$-terminal sequences (Fig. $1 B$ ).

Mutations in the protein 4.1 gene result in hereditary elliptocytosis. To date, mutations that result in elongated or shortened 4.1 polypeptides (8-12) or deficiency of red cell protein $4.1(10,13-17)$ have been described. We have previously reported that in an Algerian family, several siblings suffer from $\mathrm{HE}$ and severe hemolytic anemia caused by the complete absence of erythroid protein 4.1. These patients, the offspring of a consanguinous marriage, were homozygous for a structural rearrangement of the protein 4.1 gene located around the downstream AUG codon (3). Surprisingly, although the same gene encodes protein 4.1 isoforms in erythroid and nonerythroid tissue, no clinical manifestations other than the hemolytic ane- 


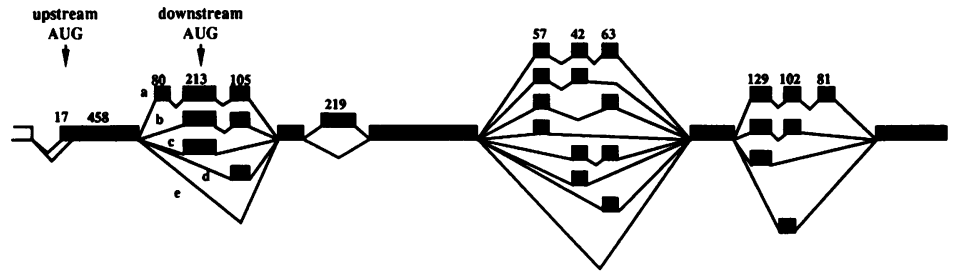

high MW

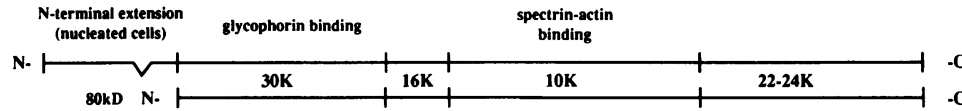

Figure 1. Major isoforms of protein 4.1 $\mathrm{mRNA}$ and protein encoded by a single 4.1 gene. $(A)$ An array of $4.1 \mathrm{mRNAs}$ can be produced by alternative splicing of RNA transcribed from the 4.1 gene. Boxes indicate individual coding units (exons) of the gene, whose length in nucleotides is indicated above each exon; lines represent splicing events between adjacent exons. Two translation initiation signals, located in two different 5 ' exons, are indicated by vertical arrows. The designations $a-e$ indicate five possible splicing pathways among exons in the region of the downstream AUG. The exact nucleotide sequence of these exons has been reported previously (5), with the exception of the 42-nucleotide exon within the 10-kD domain $(40)$. (B) Two size classes of protein 4.1 isoforms.

The 80-kD red cell protein 4.1 is translated from the downstream AUG, while utilization of the upstream site leads to synthesis of higher molecular mass isoforms in nucleated cells. The designations $30 \mathrm{~K}, 16 \mathrm{~K}$, etc., refer to the major structural domains of protein 4.1 produced by mild proteolytic digestion with chymotrypsin (41).

mia were observed. In this study, we examined the structure of the protein $4.1 \mathrm{mRNA}$ and polypeptide in the erythroid and nonerythroid cells of one of the homozygously affected siblings. The molecular lesion was shown to involve deletion of the downstream AUG in 4.1 mRNA and the absence of protein 4.1 in red cells. In contrast, isoforms that use the upstream AUG were detected in nonerythroid cells, thus explaining the absence of manifestations in other organ systems.

\section{Methods}

Subjects. The clinical and laboratory findings in this Algerian family with HE caused by deficiency of erythroid protein 4.1 has already been described (15) and its molecular basis partially characterized (3). The cells used for this study were obtained from one of the siblings who has no protein 4.1 in the red blood cells and who is homozygous for a 4.1 gene rearrangement.

Immunological analysis of protein 4.1 polypeptides in erythroid and nonerythroid cells. To analyze expression of protein 4.1 polypeptides in erythroid cells, washed red blood cells were lysed in $7 \mathrm{mM} \mathrm{NaCl}, 5 \mathrm{mM}$ Tris, pH 7.4, $1 \mathrm{mM}$ EDTA, $1 \mathrm{mM}$ diisopropyl fluorophosphate (at $4^{\circ} \mathrm{C}$ ), and proteins were solubilized in $62.5 \mathrm{mM}$ Tris, $\mathrm{pH} 6.8,2.3 \%$ SDS, $10 \%$ glycerol, and $5 \% \beta$-mercaptoethanol. Skin fibroblasts ( 5 $\times 10^{6}$ cells), cultured from the patient and a normal control, were rinsed with PBS before solubilization. Protein samples were fractionated on 7.5\% SDS-PAGE, transferred onto nitrocellulose membranes, stained with anti-protein 4.1 antibodies, and counterstained with peroxidase-conjugated secondary antibody. Immobilized antigens were detected by enhanced chemiluminescence method (Amersham Corp., Arlington Heights, IL).

For immunofluorescence microscopy, fibroblast cells were grown on glass coverslips, fixed and permeabilized in $-80^{\circ} \mathrm{C}$ acetone and then incubated sequentially in primary antibody and in FITC-conjugated goat anti-rabbit IgG.

Sequence analysis of mutant protein $4.1 \mathrm{mRNAs}$ in erythroid and nonerythroid cells. Erythroid RNA was extracted from normal control and patient reticulocytes as described previously (18). Nonerythroid RNA was prepared from skin fibroblasts and EBV-transformed B lymphocytes grown in culture. Total RNA was reverse transcribed into cDNA using MuMLV reverse transcriptase and random hexanucleotide primers; $4.1 \mathrm{cDNA}$ was then specifically amplified by polymerase chain reaction (PCR) techniques under the following conditions: denaturation at $94^{\circ} \mathrm{C}$ for $30 \mathrm{~s}$, annealing at $50^{\circ} \mathrm{C}$ for $30 \mathrm{~s}$ and extension at $72^{\circ} \mathrm{C}$ for $1 \mathrm{~min}$ and $45 \mathrm{~s}$ with initial denaturation at $94^{\circ} \mathrm{C}$ for $5 \mathrm{~min}$ and final extension at $72^{\circ} \mathrm{C}$ for $10 \mathrm{~min}$. PCR products were electrophoresed on 5\% polyacrylamide gel and then visualized with ethidium bromide staining. For nucleotide sequence analysis, PCR fragments were cloned into the EcoRI site of the plasmid vector Bluescript (Stratagene, La
Jolla, CA) and sequenced using Sequenase (U.S. Biochemical Corp., Cleveland, $\mathrm{OH}$ ) according to the manufacturer's specifications. Primers used in this study were as follows: sense strand = 5'-CAAAACAGACCCATCTTTGGATCTTCATTC-3'; antisense strand $=5^{\prime}$ TGTAAAATTCCAAGGGACACCACGAACCTG-3'.

\section{Results}

Immunological detection of protein 4.1 in nonerythroid tissues. We have previously shown that protein 4.1 is completely absent from the HE patient's red cells (15). To test for the presence of protein 4.1 in the patient's nonerythroid cells, we stained cultured fibroblasts with antibodies directed against different domains of the protein. Fig. 2 shows phase contrast photomicrographs of normal $(A)$ and patient $(D)$ fibroblasts, as well as immunofluorescence images of these cells stained with two different anti-4.1 antibodies. Antibody directed against a $\mathrm{COOH}$-terminal domain of the protein (anti 24-2) fluorescently labeled both fibroblast samples (Fig. 2, $B$ and $E$ ), indicating that patient fibroblasts do contain protein 4.1 isoform(s). Furthermore, antibody directed against the $\mathrm{NH}_{2}$-terminal extension (anti-N-1) also stained these fibroblasts (Fig. 2, $C$ and $F$ ). This latter result demonstrates that the protein 4.1 isoforms present in patient fibroblasts arose from translation initiation at the upstream AUG, and predicts that they contain species larger than the $80-\mathrm{kD}$ isoforms found in red cells.

To examine the molecular masses of protein 4.1 isoforms expressed in patient red cells and fibroblasts, we used an immunoblotting procedure on proteins that had been size-fractionated by PAGE (Fig. 3). Normal red cells exhibited immunologically crossreacting species of $\sim 80 \mathrm{kD}$ (lane 1 ), but these proteins were absent from patient red cells (lane 2). Normal fibroblasts expressed several 4.1 isoforms including a major species of $\sim 80 \mathrm{kD}$ that comigrated with the major red cell isoform (arrow), as well as higher and lower molecular mass isoforms (lane 3 ). In contrast, patient fibroblasts expressed no $80-\mathrm{kD} 4.1$ protein, but still contained the other isoforms (lane 4).

Structure of mutant protein $4.1 \mathrm{mRNA}$ in reticulocytes and in nonerythroid cells. RNA analysis was focused on the region surrounding the downstream AUG, since our earlier Southern blotting studies indicated that this region of the gene was rearranged (3). Fig. $4 B$ (lane 1 ) shows that PCR amplification of 4.1 cDNA from normal reticulocytes yielded several DNA 

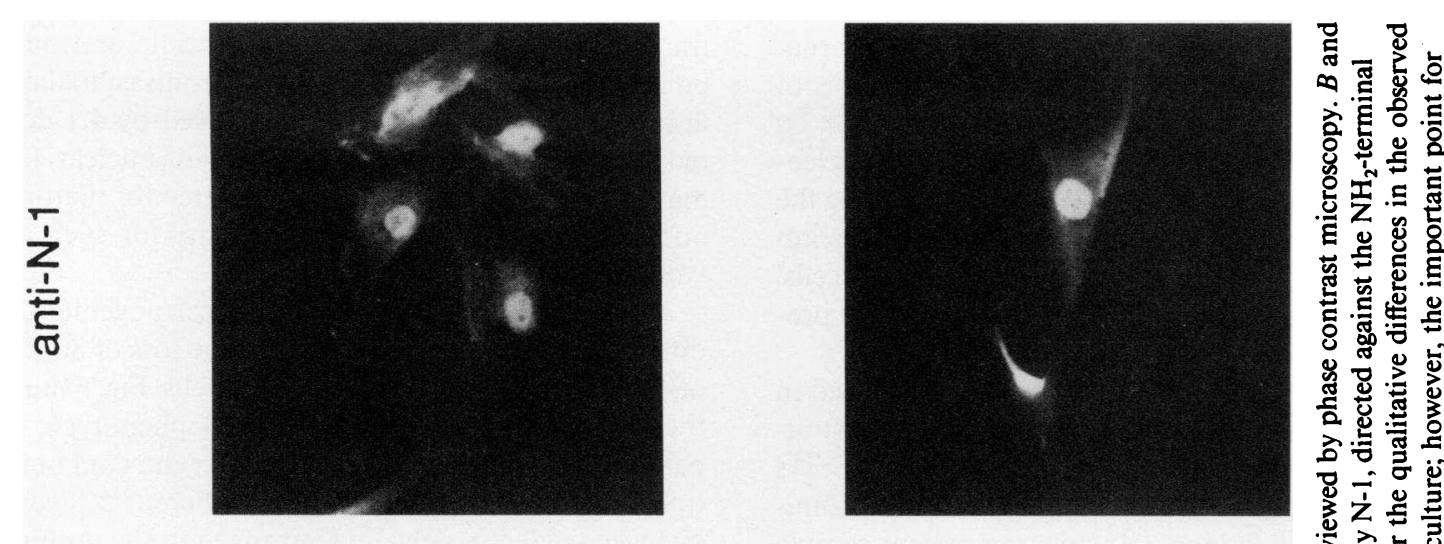

U

[5

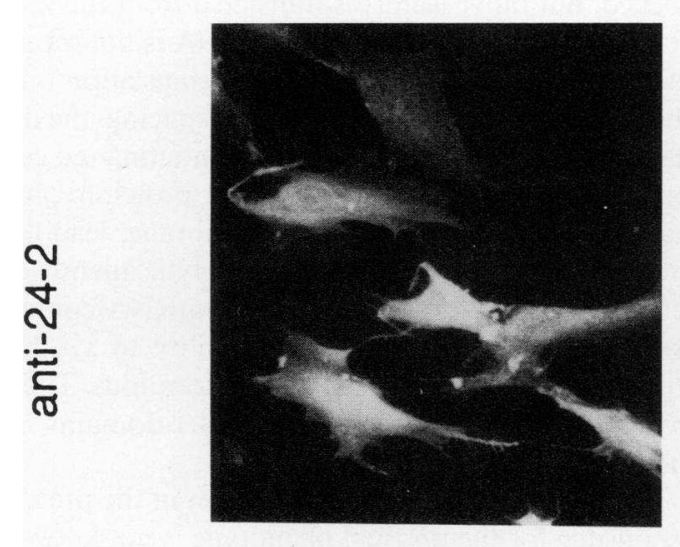

m

[a

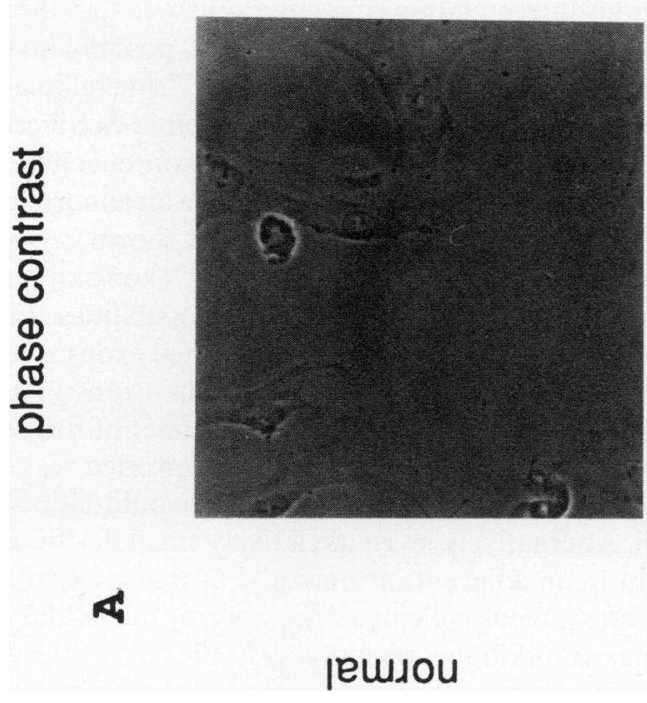

A

tue!̣ed
究

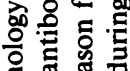
응 总究

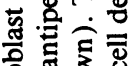
응 등 起吉的 글 율 空氜 \% 인 可造? 尝远 웜

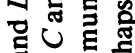
จ 的施 密安 응 졸 它焉

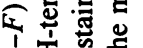

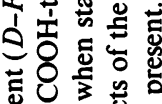
款密 语 पิ ऽ

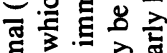
웡 过 혀줄 잉 ठ 을 을 플 哰 论

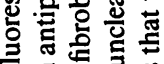
릉 要䆑 焉 Z i

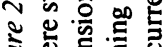

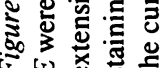


bands, representing alternatively spliced mRNA isoforms designated $a-e$ (see Fig. $1 A$ ). The most abundant isoform in normal cells is isoform $b$, which includes the downstream AUG. Normal cells also contain small amounts of 4.1 mRNA which has deleted the downstream AUG as a consequence of alternative splicing (isoform $e$ ). In contrast, $4.1 \mathrm{cDNA}$ amplified from the HE patient yielded only PCR product $e$ (Fig. $4 B$, lane 2 ). DNA sequence analysis of this product revealed a 318-nucleotide deletion caused by the absence of two exons, including the one encoding the downstream AUG. Since this downstream site is required for translation initiation in late erythroid cells, the $\mathrm{HE}$ reticulocytes are incapable of synthesizing $80-\mathrm{kD}$ protein 4.1.

The structure of protein 4.1 mRNA was next examined in both normal and HE fibroblasts, using an identical PCR strategy to amplify the region around the downstream AUG. As with reticulocytes, the normal RNA sample yielded predominantly isoform $b$ (Fig. $4 B$, lane 3 ), while the patient sample exhibited only isoform $e$ lacking the downstream AUG (Fig. 2 $B$, lane 4). When PCR was repeated using oligonucleotide primers specific for the upstream AUG, normal and patient fibroblast 4.1 mRNA amplified equally well, suggesting that they retain the potential to express high molecular 4.1 isoforms (not shown). These results, loss of the downstream AUG coupled with retention of the upstream site in $4.1 \mathrm{mRNA}$, are consistent with the immunological data showing that patient fibroblasts have selectively lost expression of $80-\mathrm{kD}$ isoforms, but not higher molecular mass isoforms (Fig. 3).

\section{Discussion}

The protein 4.1 gene is differentially regulated by a complex pattern of RNA splicing, as illustrated in Fig. 1. The major component in the red cell is an $80-\mathrm{kD}$ protein translated from the downstream AUG. In contrast, nucleated cells, including immature erythroid precursors in the bone marrow, as well as nonerythroid cell types, use an upstream translation initiation site to produce larger 4.1 isoforms having $\mathrm{NH}_{2}$-terminal extensions of 209 amino acids. While the mature $80-\mathrm{kD}$ isoform is an essential component of the membrane skeleton, where it

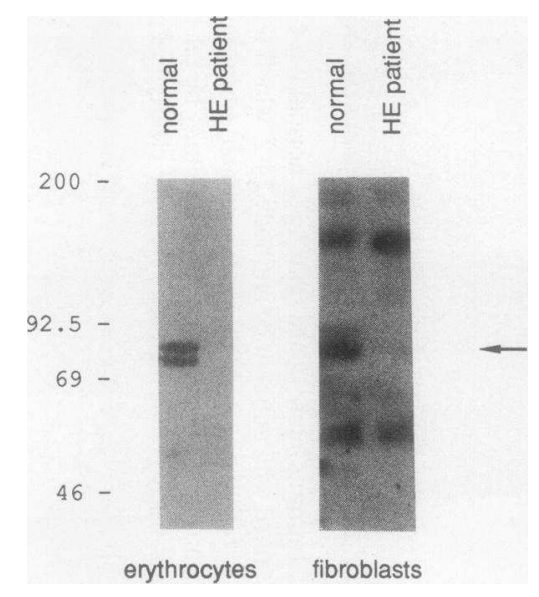

Figure 3. Western blot analysis of protein 4.1 in red cells and fibroblasts. Proteins were electrophoresed in SDS-polyacrylamide gels, transferred to nylon membranes, and immunoblotted with either polyclonal anti-4.1 antibody (lanes 1 and 2) or antipeptide antibody 24-2 (lanes 3 and 4). The immunoreactive doublet in normal erythrocytes represents two polypeptides, known as $4.1 \mathrm{a}$ and $4.1 \mathrm{~b}$, which differ slightly in molecular mass because of posttranslational modification. The results shown in this figure were confirmed with two additional antipeptide antibodies directed against other domains of protein 4.1 . plays an important role in maintaining red cell morphology and plasticity, the functions of the other 4.1 isoforms are not yet precisely known. Immunostaining of nucleated cells has shown that the larger isoforms appear localized to specific intranuclear structures including the centriole, and may be a component of a nuclear skeleton (19). In contrast to the sole manifestation of hemolytic anemia produced by 4.1 deficiency in red cells, we speculate that deficiency of nuclear 4.1 isoforms may disrupt some vital function required for maturation of all nucleated cells, and that homozygosity for such a mutation would be incompatible with life.

In the patient we studied, a gene rearrangement around the downstream AUG resulted in selective loss of $80-\mathrm{kD}$ isoforms of 4.1 in erythroid and nonerythroid cells. Fig. 5 illustrates how the mutation produces this unusual phenotype. The upper panel represents a portion of the 4.1 gene containing the two translation initiation sites in two different 5' exons. The sequences shaded in grey are rearranged in the mutant gene and deleted from the corresponding mature mRNAs shown in the lower panel. Since the deletion encompasses only one of the two potential translation initiation sites, an isoform-specific deficiency arises in which $80-\mathrm{kD}$ protein 4.1 synthesis is blocked, but other isoforms translated from the upstream site are unaffected. Reticulocyte $4.1 \mathrm{mRNA}$ is not translatable because of the absence of a functional translation initiation site (the upstream site being excluded by splicing, the downstream site by mutation). Terminally differentiating red cells are thus completely deficient in the $80-\mathrm{kD} 4.1$ protein required to mechanically stabilize the red cell membrane, leading to the altered elliptical morphology and hemolytic anemia characteristic of HE. In contrast, fibroblast 4.1 mRNA contains the upstream AUG and retains the capability to synthesize other isoform( $\mathrm{s}$ ) bearing an extended $\mathrm{NH}_{2}$ terminus. These isoforms probably retain most of the protein 4.1 domains required for nuclear function.

The precise nature of the mutation in the protein 4.1 gene responsible for the unusual phenotype is not known. In a previous study, we showed that several restriction fragment length polymorphisms (RFLPs) cosegregated with HE and protein 4.1 deficiency in this family (3). These RFLPs, which have not been observed in other normal individuals, mapped to a $5^{\prime}$ region of the gene around the downstream AUG. The most obvious interpretation of these results was that the mutant 4.1 gene had undergone a rearrangement, possibly involving a genomic deletion of one or more exons. Using radiolabeled single exon probes for hybridizing to genomic Southern blots, we have recently determined that the exon encoding the downstream AUG, although detected within an abnormal restriction fragment, is not deleted (results not shown). Nondeletional mechanisms that might produce an "exon-skipping" phenotype include at least two obvious possibilities. First, a gross genomic inversion spanning the affected exons would alter the regional restriction map and place the exons in an antisense orientation with respect to the remainder of the gene. During pre-mRNA processing, exons in the inverted region would be skipped because the splicing signals would all be inverted as well. Alternatively, even a relatively small deletion/rearrangement in an adjacent intron could, if it altered critical splicing signal(s), block splicing of neighboring exons and produce the same exon skipping phenotype. In the case of the downstream AUG, this exon is skipped at a low frequency, even during normal 4.1 pre-mRNA processing, and a splicing mutation could alter the balance so as to produce a very high frequency 


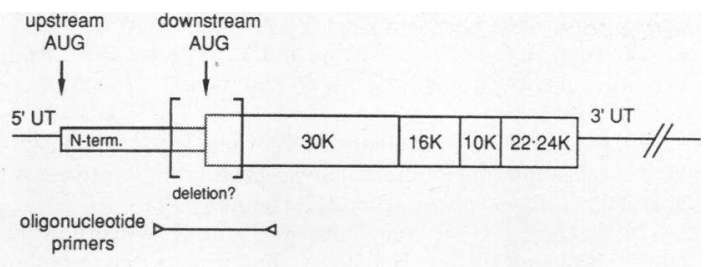

B

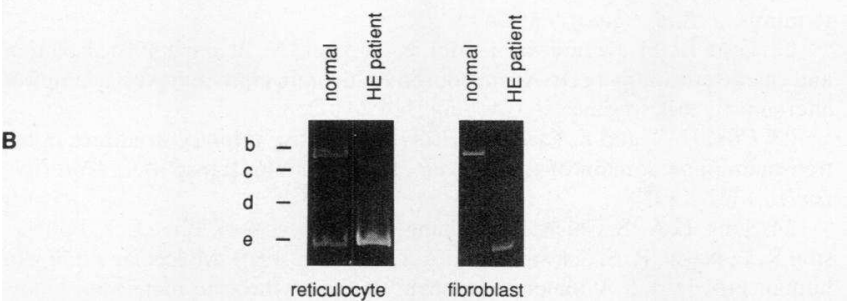

Figure 4. Amplification of 4.1 mRNA sequences flanking the downstream AUG. $(A)$ The top panel represents a composite 4.1 mRNA showing untranslated sequences ( $U T$ ), the $80-\mathrm{kD}$ coding sequences (wide box), and the $\mathrm{NH}_{2}$-terminal extension of high molecular mass isoforms (narrow box). The brackets enclose the region implicated in earlier studies as being deleted or rearranged in the mutant 4.1 mRNA. Arrowheads indicate the position of oligonucleotides used to amplify 4.1 mRNA sequences. ( $B$ ) PAGE of the amplified DNA fragments. The designations $b-e$ correspond to the isoforms shown in Fig. 1; isoform $a$ amplifies very poorly and is not shown.

of skipping. Our results cannot unambiguously distinguish between these possibilities. However, the abundance of observed RFLPs (reference 3; data not shown) suggests that the rearrangement involves kilobases of DNA rather than a small sequence change near intron/exon boundaries.

Characterization of red cells from other $\mathrm{HE}$ individuals performed in several laboratories around the world indicate that defects in 4.1 function commonly underlie the HE phenotype. Two broad classes of mutation have been observed. One class, sometimes referred to as $4.1(-) \mathrm{HE}$, is characterized by quantitative deficiencies of protein $4.1(10,13-17)$. Generally these are only partial deficiencies and thus affected individuals do not suffer the severe hemolytic anemia observed in the homozygous deficient Algerian family members. In the other class of mutation, $4.1(+) \mathrm{HE}, 4.1$ protein is present but is qualitatively altered in structure $(8-11,20)$. Biophysical studies show that both classes of mutation decrease membrane stability and deformability $(11,12,15,20)$. Molecular analyses of protein 4.1 mutations have revealed an interesting spectrum of genetic defects affecting protein 4.1 gene expression, including apparent duplication and deletion of internal exons $(8-11,20)$.

Given the complex patterns in which many human genes are regulated, the potential for genetic mutations exhibiting pleiomorphic phenotypic effects is enormous. Even in the relatively uncomplicated red cell membrane, multiple examples of alternatively spliced genes exhibiting differential expression in erythroid versus nonerythroid cells have been found, including $\beta$-spectrin (21), ankyrin (22), band 3(23), band 4.2(24), and glycophorin C (25). Defects in these genes are known to produce disorders affecting red cell morphology and mechanical integrity, and may in some cases exhibit abnormal phenotypes in nonerythroid tissues as well. For example, deficiency of the erythroid ankyrin protein can generate spherocytosis in humans and normoblastosis in mice $(26,27)$. The erythroid ankyrin gene is spliced in several different patterns and is expressed in brain as well as erythroid cells. Interestingly, mice with the normoblastosis mutation have recently been shown to exhibit deficiency of certain ankyrin isoforms in brain in concert with neurologic abnormalities $(28,29)$. In the case of $\beta$ spectrin (21), this protein is abnormal or deficient in a subset of human elliptocytosis patients and in the mouse mutant known as jaundiced. Since the $\beta$-spectrin gene is spliced differently in erythroid versus muscle cells, the potential exists for regulatory mutations which could exhibit unusual phenotypes.

Beyond the red cell membrane, alternative splicing has been described in a wide variety of other genes, some of which are also differentially expressed in erythroid vs. nonerythroid cells. One of the first reported examples involves the gene encoding porphobilinogen deaminase (PBGD), the third enzyme in the heme biosynthetic pathway. A variant form of acute intermittent porphyria, characterized by normal red cell levels of the PBGD enzyme, can be generated by a mutation having an effect converse to that described in this paper. That is, expression of an upstream AUG required for translation of nonerythroid PBGD is disrupted, while a downstream AUG used in erythroid cells is expressed normally $(30,31)$.

Many other variations on this theme are likely to be uncovered in the future, as the list of known alternatively spliced genes has grown enormously in the past few years. Vital intracellular structural proteins such as tropomyosin (32), myosin (33), and troponin (34), cell surface integrin (35) and growth factor receptors (36), cellular proto-oncogenes (37-39), and numerous others can be spliced in tissue- or development-specific patterns. Since many of these genes are required for cellular function, mutations that totally block gene expression

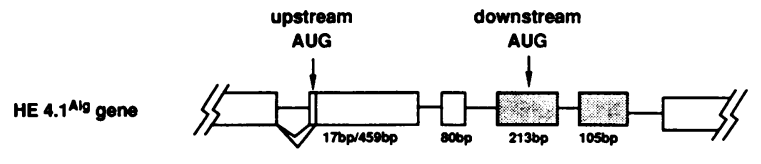

reticulocyto 4.1 Alg mRNA

fibroblast 4.1 ${ }^{\text {Alg }}$ MRNA

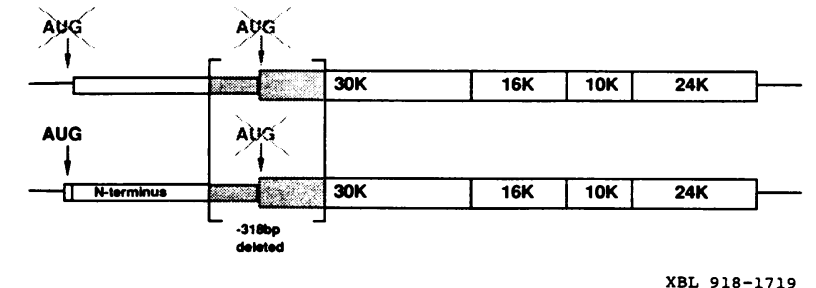

Figure 5. Model of the isoform-specific deficiency encoded by the aberrant 4.1 gene. The upper panel shows a 5 ' portion of the 4.1 gene, including the exons encoding the upstream and downstream AUGs. In the mutant gene, exons in grey are not spliced into 4.1 mRNAs. Reticulocyte 4.1 mRNA thus lacks any functional translation initiation site and cannot make any protein 4.1. Fibroblast $4.1 \mathrm{mRNA}$ retains the upstream AUG and can therefore synthesize high molecular mass 4.1 isoforms with the $\mathrm{NH}_{2}$-terminal extension. 
might well be lethal. However, mutations in alternatively spliced exons can have more subtle effects. At the molecular level, genetic alterations of this type might disrupt expression of isoforms only in selected tissues; patients inheriting such a mutation might well exhibit an unusual phenotype with tissuespecific manifestations.

\section{Acknowledgments}

The authors would like to acknowledge the invaluable assistance of Dr. C. Wallon and Dr. A. Boutron in establishing the B-cell and fibroblast cultures.

This work was supported by a grant from the National Institutes of Health (DK-32094) and by the Director, Office of Health and Environmental Research, Division of the U.S. Department of Energy, under contract DE-AC03-76SF00098.

\section{References}

1. Davies, K. A., and S. E. Lux. 1989. Hereditary disorders of the red cell membrane skeleton. Trends Genet. 5:222-227.

2. Anderson, R. A., I. Correas, C. Mazzucco, D. E. Castle, and V. T. Marchesi 1988. Tissue-specific analogues of erythrocyte protein 4.1 retain functional domains. J. Cell. Biochem. 37:269-284.

3. Conboy, J. G., N. Mohandas, G. Tchernia, and Y. W. Kan. 1986. Molecular basis of hereditary elliptocytosis due to protein 4.1 deficiency. N. Engl. J. Med. 315:680-685.

4. Conboy, J. G., J. Chan, N. Mohandas, and Y. W. Kan. 1988. Multiple protein 4.1 isoforms produced by alternative splicing in human erythroid cells. Proc. Natl. Acad. Sci. USA. 85:9062-9065.

5. Conboy, J. G., J. Chan, J. A. Chasis, Y. W. Kan, and N. Mohandas. 1991 Tissue- and development-specific alternative RNA splicing regulates expression of multiple isoforms of erythroid membrane protein 4.1. J. Biol. Chem 266:8273-8280.

6. Tang, T. K. T. L. Leto, I. Correas, M. A. Alonso, V. T. Marchesi, and E. J Benz. 1988. Selective expression of an erythroid-specific isoform of protein 4.1. Proc. Natl. Acad. Sci. USA. 85:3713-3717.

7. Tang, T. K., T. Leto, V. T. Marchesi, and E. J. Benz. 1990. Heterogeneity of mRNA and protein products arising from the protein 4.1 gene in erythroid and nonerythroid tissues. J. Cell Biol. 110:617-624.

8. Alloisio, N., E. Dorleac, J. Delauney, et al. 1982. A shortened variant of red cell membrane protein 4.1. Blood. 60:265-267.

9. Morle, L., M. Garbarz, N. Alloisio, R. Girot, I. Chaveroche, P. Boivin, and J. Delauney. 1985. The characterization of protein 4.1 Presles, a shortened variant of RBC membrane protein 4.1. Blood. 65:1511-1517.

10. McGuire, M., B. L. Smith, and P. Agre. 1988. Distinct variants of erythrocyte protein 4.1 inherited in linkage with elliptocytosis and $R$ h type in three white families. Blood. 72:287-293.

11. Marchesi, S., J. Conboy, P. Agre, J. T. Letsinger, V. T. Marchesi, D. W. Speicher, and N. Mohandas. 1990. Molecular analysis of insertion/deletion mutations in protein 4.1 in elliptocytosis. I. Biochemical identification of rearrangements in the spectrin/actin binding domain and functional characterizations. $J$. Clin. Invest. 86:516-523.

12. Conboy, J., S. Marchesi, R. Kim, P. Agre, Y. W. Kan, and N. Mohandas. 1990. Molecular analysis of insertion/deletion mutations in protein 4.1 in elliptocytosis. II. Determination of the molecular genetic origins of rearrangements. $J$. Clin. Invest. 86:524-530.

13. Alloisio, N., L. Morle, E. Dorleac, O. Gentilhomme, D. Bachir, D. Guetarni, P. Colonna, B. M., Z. Zouaoui, L. Roda, D. Roussel, and J. Delauney. 1985. The heterozygous form of $4.1(-)$ hereditary elliptocytosis [ the $4.1(-)$ trait]. Blood. 65:46-51.

14. Mueller, T. J. and M. Morrison. 1990. Glycononnectin (PAS 2), a membrane attachment site for the human erythrocyte cytoskeleton. In Erythrocyte Membrane 2: Clinical and Experimental Advances. W. C. Kruckenberg, J. W. Eaton, and G. J. Brewer, editors. Alan R. Liss Inc., New York, p. 95-116.

15. Tchernia, G., N. Mohandas, and S. B. Shohet. 1981. Deficiency of skeletal membrane protein 4.1 in homozygous hereditary elliptocytosis. J. Clin. Invest. 68:454-460.

16. Lambert, S., J. Conboy, and S. Zail. 1988. A molecular study of heterozygous protein 4.1 deficiency in hereditary elliptocytosis. Blood. 72:1926-1929.

17. Feddal, S., G. Brunet, L. Roda, S. Chabanis, N. Alloisio, L. Morle, M. T. Ducluzeau, J. Marechal, J. M. Robert, E. J. Benz, et al. 1991. Molecular analysis of hereditary elliptocytosis with reduced protein 4.1 in the French Northern Alps. Blood. 78:2113-2119.
18. Temple, G. F., J. C. Chang, and Y. W. Kan. 1977. Authentic $\beta$-globin mRNA sequences in homozygous $\beta^{0}$ thalassemia. Proc. Natl. Acad. Sci. USA. 74:3047-3051.

19. Marchesi, V. T., S. Huang, T. K. Tang, and E. J. J. Benz. 1990. Intranuclear localization of high molecular weight isoform of protein 4.1 generated by alternative mRNA splicing. Blood. 76(Suppl.) 1:12a.

20. Conboy, J. G., R. Shitamoto, M. Parra, R. Winardi, A. Kabra, J. Smith, and N. Mohandas. 1991. Hereditary elliptocytosis due to both qualitative and quantitative defects in membrane skeletal protein 4.1. Blood. 78:2438-2843.

21. Winkelmann, J. C., F. F. Costa, B. L. Linzie, and B. G. Forget. 1990. Beta spectrin in human skeletal muscle. Tissue-specific differential processing of $3^{\prime}$ beta spectrin pre-mRNA generates a beta spectrin isoform with a unique carboxyl terminus. J. Biol. Chem. 265:20449-20454.

22. Otto, E., M. Kunimoto, T. McLaughlin, and V. Bennett. 1991. Isolation and characterization of cDNAs encoding human brain ankyrins reveal a family of alternatively spliced genes. J. Cell Biol. 114:241-253.

23. Cox, J. V., and E. Lazarides. 1988. Alternative primary structures in the transmembrane domain of the chicken erythroid anion transporter. Mol. Cell. Biol. 8:1327-1335.

24. Sung, L. A., S. Chien, L.-S. Chang, K. Lambert, S. A. Bliss, E. E. Bouhassira, R. L. Nagel, R. S. Schwartz, and A. C. Rybicki. 1990. Molecular cloning of human protein 4.2: A major component of the erythrocyte membrane. Proc. Natl. Acad. Sci. USA. 87:955-959.

25. Le Van Kim, C., M. T. Mitjavila, M. Clerget, J. P. Cartron, and Y. Colin 1990. An ubiquitous isoform of glycophorin $C$ is produced by alternative splicing. Nucleic Acids Res. 18:3076.

26. Lambert, S., H. Yu, J. T. Prchal, J. Lawler, P. Ruff, D. Speicher, M.-C. Cheung, Y. W. Kan, and J. Palek. 1990. cDNA sequence for human erythrocyte ankyrin. Proc. Natl. Acad. Sci. USA. 87:1730-1734.

27. Lux, S. E., K. M. John, and V. Bennett. 1990. Analysis of cDNA for human erythrocyte ankyrin indicates a repeated structure with homology to tissue-differentiation and cell-cycle control proteins. Nature (Lond.). 344:36-42.

28. Peters, L. L., C. S. Birkenmeier, R. T. Bronson, R. A. White, S. E. Lux, E. Otto, V. Bennett, A. Higgins, and J. E. Barker. 1991. Purkinje cell degeneration associated with erythroid ankyrin deficiency in $\mathrm{nb} / \mathrm{nb}$ mice. J. Cell Biol. 114:1233-1241.

29. Kordeli, E., and V. Bennett. 1991. Distinct ankyrin isoforms at neuron cell bodies and nodes of Ranvier resolved using erythrocyte ankyrin-deficient mice. J. Cell Biol. 114:1243-1259.

30. Grandchamp, B., V. H. De, C. Beaumont, S. Chretien, O. Walter, and Y. Nordmann. 1987. Tissue-specific expression of porphobilinogen deaminase. Two isoenzymes from a single gene. Eur. J. Biochem. 162:105-110.

31. Grandchamp, B., C. Picat, R. Kauppinen, V. Mignotte, L. Peltonen, P. Mustajoki, P. H. Romeo, M. Goossens, and Y. Nordmann. 1989. Molecular analysis of acute intermittent porphyria in a Finnish family with normal erythrocyte porphobilinogen deaminase. Eur. J. Clin. Invest. 19:415-418.

32. Helfman, D. M., R. F. Roscigno, G. J. Mulligan, L. A. Finn, and K. S Weber. 1990. Identification of two distinct intron elements involved in alternative splicing of b-tropomyosin pre-mRNA. Genes \& Dev. 4:98-110.

33. Kronert, W. A., K. A. Edwards, E. S. Roche, L. Wells, and S. I. Bernstein 1991. Muscle-specific accumulation of Drosophila myosin heavy chains: a splicing mutation in an alternative exon results in an isoform substitution. EMBO (Eur. Mol. Biol. Organ.) J. 102479:88.

34. Breitbart, R. E., H. T. Nguyen, R. M. Medford, A. T. Destree, V. Mahdavi, and B. Nadal-Ginard. 1985. Intricate combinatorial patterns of exon splicing generate multiple regulated troponin $\mathrm{T}$ isoforms from a single gene. Cell. 41:67-82.

35. Tamura, R. N., H. M. Cooper, G. Collo, and V. Quaranta. 1991. Cell type-specific integrin variants with alternative $\alpha$ chain cytoplasmic domains. Proc. Natl. Acad. Sci. USA. 88:10183-10187.

36. Werner, S., D. S. R. Duan, C. Devries, K. G. Peters, D. E. Johnson, and L. T. Williams. 1992. Differential splicing in the extracellular region of fibroblast growth factor receptor generates receptor variants with different ligand-binding specificities. Mol. Cell. Biol. 12:82-88.

37. Shen, O. G., R. J. Skurla, J. D. Owens, and J. F. Mushinski. 1990. Alternative splicing of RNAs transcribed from the human c-myb gene. Mol. Cell. Biol. 10:2715-2722.

38. Westin, E. H., K. M. Gorse, and M. F. Clarke. 1990. Alternative splicing of the human c-myb gene. Oncogene. 5:1117-1124.

39. Dasgupta, P., and E. P. Reddy. 1989. Identification of alternatively spliced transcripts for human c-myb: molecular cloning and sequence analysis of human c-myb exon 9A sequences. Oncogene. 4:1419-1423.

40. Benz, E. J., T. K. Tang, F. Baklouti, H. Huang, J. Cho, and V. T. Marchesi. 1991. Tissue specific selection of alternatively spliced exons of the protein 4.1 gene generates multiple isoforms with altered spectrin actin binding domains. Blood. 78:365a. (Abstr.).

41. Leto, T. L., and V. T. Marchesi. 1984. A structural model of human erythrocyte protein 4.1. J. Biol. Chem. 259:4603-4608. 